\title{
EAST AFRICAN VIRUS RESEARCH INSTITUTE
}

\begin{abstract}
CHE annual report* of the East African Virus Research Institute, Entebbe, for 1956-57, which includes a list of papers published during the year and a list of scientific and technical staff as at June 30, 1957, records that the mechanism of transmission and maintenance in Nature of the arthropod-borne viruses continue to be the main interest of the Institute. A systematic programme was commenced to identify the viruses concerned in the causation of fever in man in Uganda. Rabies were recorded in the Entebbe area for the first time and the Institute was largely responsible for identifying the agent. Studies on Arvicanthis abyssinicus, a common rodent in Uganda, indicated that it may be important as a host in maintaining Rift Valley fever virus in Nature. Two strains of Zika virus were isolated from Aedes africanus mosquitoes collected in forest near Entebbe.

Much att ention continued to be given to yellow fever. Some modifications were made in yellow fever neutralization test methods. A more detailed analysis of the sera collected in Northern Rhodesia in 1950-52 indicates that in the four districts mainly involved both sexes are exposed to infection, but rates are generally higher in males than in females; in males infection-rates generally increase with age. In several tribes or localities this is true of females only up to

- East Africa High Commission. East African Virus Research Institute Report, July 1956-June 1957. Pp. iv +61. (Nairobi Government Printer, 1957.) Sh. 5 .
\end{abstract}

about twenty-four years of age. Twenty-five monkey sera from Tanganyika were all non-immune, but five immune individuals were found among thirteen Brazza's monkeys (Cercopithecus neglectus), and laboratory studies indicated that this monkey was likely to be an efficient host for yellow fever virus in Nature. No antibody could be detected in the study of the hæmagglutination inhibition antibody reaction of a bush-baby (Galago crassicaudatus) on infection with yellow fever virus.

In the entomological field most attention has been devoted to mosquitoes, especially Aedes (Stegomyia) spp. The intermittent trap for sampling insects attracted to live bait continued to give encouraging results. Studies are reported of the oviposition cycle in Aedes aegypti, A. africanus and Taeniorhynchus fuscopennatus and of the hormonal mechanisms involved in the reproductive cycle of mosquitoes. Extensive studies of Aedes aegypti both in Entebbe and on the Kenya coast, to determine whether the population of this species is made up of 'races' differing biologically, indicate that man is an $\mathrm{im}$ portant host both in Uganda and on the Kenya coast. The hosts of some other mosquitoes have been determined: A. simpsoni feeds mainly on man; Taeniorhynchus fuscopennatus feeds mainly on mammals and the other Taeniorhynchus spp. attack mainly birds.

\section{ARIZONA METEORITE CRATER}

$\mathrm{D}^{2}$ URING the summer of 1956 the Smithsonian Astrophysical Observatory sent an expedition to investigate the distribution of pieces of meteoritic material that are scattered through the mantle of soil surrounding the Arizona Meteorite Crater, the object being to determine more accurately the mass of the meteorite that made the crater and also the direction of its flight. J. S. Rinehart has now published the results of this survey (Smithsonian Contributions to Astrophysics, 2, No. 7: "Distribution of Meteoritic Debris about the Arizona Meteorite Crater". Pp. ii 145-160. Washington, D.C. : Government Printing Office, 1958. 20 cents). Niniger had previously worked on the same subject and had published his results in 1956 with his method for extracting the meteoritic material from the soil surrounding the crater, but Rinehart's method was different. He developed a special magnetic separator consisting basically of a vibrating hopper and a slanted trough down which the soil moves under the combined action of gravity and vibration. Above the trough were suspended three strong 'Alnico' magnets to which the magnetic material flies up and adheres as the soil moves downwards. Many precautions were necessary to secure reliable results and these are described very fully.

Estimates of the total mass of finely divided meteoritic material around the crater suggested that this is about 12,000 tons, but this figure is subject to some uncertainty. It is believed that about onefourth of this mass may be terrestrial oxygen that combined with the meteoric iron after its encounter with the Earth. In addition, there does not appear to be any way for ascertaining accurately the amount of contaminating material present. After taking into consideration a number of uncertain factors, it is believed that the computed mass of 12,000 tons may have to be reduced by about $10-20$ per cent.

It is suggested that the meteorite approached the Earth from a south-westerly direction, and after the collision threw forward large quantities of meteoritic material to the position where it now rests. As no piece more massive than $2,000 \mathrm{lb}$. has ever been found, while thousands of pieces weighing a few ounces or less have been recovered, it is believed that the meteorite was shattered into fragments when it struck the Earth, melting and evaporation accompanying this disintegration. The results so far provide no indication as to whether a large mass of meteoritic material lies buried in the crater. If we accept the low estimates of $10,000-15,000$ tons for the mass needed to form the crater, then no large mass could remain in the crater. If, on the other hand, the estimates of Öpik and of Rostoker are nearer the true value, then the amount of meteoritic debris so far recovered is insignificant, and a large mass may be buried underneath. Dr. F. L. Whipple, in a personal communication to the author, expresses the view that a most reasonable mass is that given recently by Hill and Gilvarry, namely, between 80,000 and 400,000 tons. 